\title{
Understanding the Externalizing Behavior of School-Age Boys: The Role of a Mother's Mentalization and Attachment
}

\author{
Karolina Dejko-Wańczyk (i) ${ }^{1} \cdot$ Bernadetta Janusz ${ }^{1} \cdot$ Barbara Józefik $^{2}$
}

Published online: 14 September 2019

(c) The Author(s) 2019

\begin{abstract}
Objectives Externalizing behavior problems are considered to be a serious impediment to a child's development, and therefore it is important to identify their predictors. In this study, we investigated the connections between school-aged boys' externalizing problems, the mother's reflective functioning (RF) and the mother's perception of her childhood relationship with her own caregivers.

Methods The study sample comprised 39 school-age boys diagnosed with externalizing behavior problems together with their mothers. A child's psychopathology was assessed using the Child Behavior Checklist and Teacher Report Form. Our assessment of the mothers' mentalizing capacities was based on the Adult Attachment Interview and Reflective Functioning Scale. The perception of a mother's childhood relationship with her parents was assessed using the Parental Bonding Instrument.

Results The analysis revealed that more severe cases of aggressive and rule-breaking behavior in boys were associated with lower RF in mothers, as well as with a mother's perception of her childhood relationship with her own parents as less autonomous. More aggressive behavior in boys was also associated with a mother's perception of herself as experiencing a higher degree of care from her father during her own childhood.

Conclusions These are only preliminary findings and we have discussed them with a view to understanding the possible ways in which a mother's RF and the intergenerational context of relationship quality are associated with externalizing behavior problems in middle childhood.
\end{abstract}

Keywords Mentalization $\cdot$ Reflective function $\cdot$ Disruptive behavior $\cdot$ Externalizing behavior problems $\cdot$ Transgenerational patterns

Externalizing behavior problems are the most common psychiatric and psychotherapeutic diagnoses reported for children. Their prevalence rate varies between 5 and $10 \%$ of children aged 8-16 (Cepeda 2012; Denham et al. 2000; Hill 2002). Oppositional, aggressive and hyperactive behavior cause considerable distress in children and their families, are associated with educational failure and social problems, and often lead to antisocial behavior, substance abuse,

Karolina Dejko-Wańczyk

karolina.dejko@gmail.com

1 Family Therapy and Psychosomatics Department, Chair of Psychiatry, Faculty of Medicine, Jagiellonian University Medical College, Mikołaj Kopernik Street 21a, Cracow 31-501, Poland

2 Laboratory of Psychology and Systemic Psychotherapy, Chair of Psychiatry, Faculty of Medicine, Jagiellonian University Medical College, Cracow, Poland criminality, personality problems and mental health disorders in later life (Hill et al. 2007; Stormshak et al. 2000). Due to their prevalence, stability over time, cumulative character and the severity of their developmental consequences, externalizing behavior problems constitute a major challenge for health care (Yates et al. 2010). Externalizing problems typically peak in toddlerhood and decrease by school entry. However, some children do not exhibit this normative decline in middle childhood (Hill et al. 2006). Therefore, research focused on understanding its predictors and developmental course in this period is crucial for formulating interventions aimed at treatment and prevention.

A child's growing independence in its relationship with its parents and the development of his or her agency and autonomy in the context of learning social and academic skills are considered to be the main developmental challenges in middle childhood (between 6 and 12 years of age; 
Bosmans and Kerns 2015; Namysłowska 2004). A child's growing autonomy, the growing complexity and opaqueness of his mental states, as well as his ability to dissimulate emotion make it more challenging for parents to make sense of his experience (Borelli et al. 2016). On the other hand, despite a child's growing autonomy, parents remain his primary attachment figures, providing a secure base and safe haven when needed (Bosmans and Kerns 2015). Gender also appears to be an important context for understanding the difficulties experienced by children and their parents. Disruptive behavioral problems are more common in boys than in girls (Cepeda 2012; Egeland and Kreutzer 1991; Hill et al. 2007; Yates et al. 2010), as school-age boys have poorer emotional and behavioral regulation skills than girls (Weis et al. 2013). For this reason, parental ability to understand a child's, and particularly a boy's disruptive behavior in context of underlying emotions seems to be an important issue.

Difficulties in the mother-child relationship have received increased attention as a risk factor in the development of child psychopathology (Bowlby 1973; Ensink et al. 2016; White and Renk 2012) and the parental contribution to this problem has been shown to be even more influential in the case of children whose initial problems lie within a clinical range comparable to children without such problems (Denham et al. 2000; Stormshak et al. 2000). Mother's mentalization is considered to be an important predictor of children's externalizing behavior problems (Ensink et al. 2016, 2017; Sharp et al. 2007). Mentalization is defined as the ability to understand one's own and other people's behavior in terms of intentional mental states (Allen et al. 2008; Fonagy et al. 2002). In the context of the parent-child relationship, good mentalizing promotes affect self-regulation in a parent, results in a better understanding of a parent's complex interactions with a child, and also helps ensure more contingent responses towards the child (Sharp and Fonagy 2008; Slade et al. 2005; Suchman et al. 2010). Consequently, a parent's mentalization is fundamental to the development of a child's self-organization, self-control, agency, and affect regulation (Fonagy and Target 1997; Fonagy 2004a; Sharp and Fonagy 2008).

Mentalization is a complex construct and it can be measured by means of self-reporting (Fonagy et al. 2016; Hausberg et al. 2012), observing interactions (Ensink et al. 2017; Sharp and Fonagy 2008), and analyzing narration. Within the framework of attachment-focused research based on narration analysis, it has been operationalized as (1) an adult's general Reflective Functioning (RF) coded from the Adult Attachment Interview (AAI), which focuses on reflecting an individual's childhood experiences with his or her caregivers (Fonagy et al. 1991, 1998), or (2) parental RF, which is coded from the Parental Development Interview (PDI; Slade 2005). Both operationalizations proved to be valid in parent-child relationship research, as various studies show a link between low RF in a mother and a child's attachment insecurity and behavioral problems (Camoirano 2017; Ensink et al. 2016; Fonagy et al. 1991; Grienenberger et al. 2005; Meins et al. 2013; Smaling et al. 2016, 2017). In this study, we decided to measure general RF in mothers, because we assumed that in the context of a child's externalizing behavior problems, a mother's selfregulatory skills might play a fundamental role. A child's provocative or disobedient behavior often evokes feelings of frustration, anger, helplessness or guilt. Such negative emotions, when linked with compromised mentalization, can pose a challenge to a mother's emotion regulation system. This may lead to harsher parenting responses towards a child (Denham et al. 2000; Mazursky-Horowitz et al. 2015), less parental effort put into teaching a child to understand his own emotional experiences (Katz and Windecker-Nelson 2004), and consequently leads to a higher risk of a child's externalizing behavior problems (Beyers et al. 2003; Gershoff 2002).

A mother's capacity for mentalization is embedded in her own attachment history (Fonagy et al. 2002). The quality of a mother's early relationship with her parents has an impact on the emotional content of her mental representations of close relationships, as well as on their accessibility and flexibility (Main 1993). It affects the activation or deactivation of attachment strategies and the ability to think about emotions in moments of higher arousal (Fonagy et al. 2011), which is highly important in the context of parenting (Fonagy and Target 1997; Main 1993). Also, the intergenerational context of affect regulation in the parent-child relationship needs to be taken into account. This has been described in systemic models as the repetition of relational patterns in subsequent generations (Bowen 1978; McGoldrick et al. 1999). Research has demonstrated a crossgenerational continuity in externalizing behavior problems (Bailey et al. 2009), as well as a high level of intergenerational stability in attachment and mentalization skills (Fonagy et al. 2002; Rosso et al. 2015; Van IJzendoorn 1995). Parenting is regarded as a modulator of environmental and genetic risk underlying the intergenerational transmission of patterns of aggression (Fonagy 2004b). Hence, the reflective functioning of parents appears to be an important area of research.

While a large number of studies have been conducted on the associations between mother's mentalization skills, her attachment style and a child's psychosocial functioning in infancy and early childhood (Camoirano 2017; Centifanti et al. 2016; Fonagy et al. 1991; Grienenberger et al. 2005; Meins et al. 2013; Smaling et al. 2016, 2017), studies focusing on the later stages of a child's development are scarce (Benbassat and Priel 2012; Bizzi et al. 2019; Borelli et al. 2016; Esbjørn et al. 2013; Sharp et al. 2007). 
Nevertheless, the importance of research on parent's reflective function and child's psychosocial functioning in middle childhood cannot be overlooked, as it provides an opportunity for extending the scope of earlier research on mentalization in parents (Borelli et al. 2016). Furthermore, our paper addresses the issue of children who do not exhibit a normative decline in problematic behavior as they enter and progress through middle childhood (Hill et al. 2006). The developmental stage of middle childhood offers new challenges for both the child and his parents (Bosmans and Kerns 2015), especially when emotion and behavior regulation difficulties are already present (Denham et al. 2000; Stormshak et al. 2000). We focused on boys because they are at a higher risk of displaying externalizing behavior problems than girls (Cepeda 2012; Hill 2002). We decided to examine a mother's adult RF as we assumed that a mother's understanding of her own internal reality results in more efficient regulation of her own emotions while confronting a child's aggressive or disobedient behavior (Denham et al. 2000; Fonagy et al. 2002). Mothers who can engage in RF have more information that allows them to respond sensitively to the child (Borelli et al. 2016). By including in our study the adult RF of mothers measured with AAI-RF, we were able to assess the extent to which a mother's reflective functioning is associated with a child's behavioral problems, independently of the influence exerted by a child's temperament and a child's other personal features (Camoirano 2017). This would not be possible if maternal RF was measured with PDI. Moreover, research on a parent's general RF in the context of a child's development is limited. Despite the promising results reported by the pioneering London Parent-Child Project (Fonagy et al. 1991), so far only few papers (e.g. Arnott and Meins 2007; Ensink et al. 2016; Esbjørn et al. 2013) have applied AAIRF in research on child's development (Camoirano 2017).

In light of mentalization theory and research, the model used in our study involves associations between a mother's adult RF level, her attachment to her own childhood caregivers and a child's behavioral problems. We assume that these associations are mediated by the mother's emotion regulation and parental practices (Denham et al. 2000), as well as by the child's mentalization and emotion regulation (Sharp and Fonagy 2008). However, we did not examine these mediating factors in our study. The first aim of our study was to assess the level of RF in mothers whose sons display externalizing behavior problems at the clinical level. We hypothesized that the mothers included in the study would have weak general mentalizing capacities. Our second aim was to analyze the associations between the severity of externalizing behavior problems in school-age boys and a mother's adult RF, as well as a mother's perception of her childhood relationship with her parents. We hypothesized that more severe externalizing behavior problems in children would be associated with lower RF in mothers, as well as with a mother's perception of the poorer quality of her relationship with her own caregivers.

\section{Method}

\section{Participants}

The sample consisted of 39 mother-child dyads. The participants were recruited through the Mental Health Centre for Children and Adolescents (64\%), the Family and Child Psychotherapy Institute (10\%), the Community Day Care Centre (8\%) and school psychologists' referrals (18\%).

All the children were male and aged 7-10 years old $(M=8.41, S D=0.78)$. Alongside a child's age and gender, the third inclusion criterion was the presence of externalizing behavior problems (aggressive, oppositional, rulebreaking, impulsive or hyperactive behavior). Behavioral problems were assessed by means of a clinical interview conducted by a child and adolescent psychiatrist or clinical psychologist. The main exclusion criteria were pervasive developmental disorders, mental retardation or psychotic disorders in a child as well as a mother's current substance abuse.

The mean age of the mothers was $35.74(S D=4.71$, range 25-44). Thirty-one percent of them had completed higher education, $38 \%$ secondary education and $31 \%$ primary or vocational education. All of the participants were Caucasian, of whom $90 \%$ lived in large cities, and $94 \%$ declared themselves to have average or good financial situation. All the participants but one were primary caregivers of their children from their birth, and $72 \%$ of the women had raised the child in a two-parent family unit. Most of the mothers participating in the study (87\%) had never parted with their child for any long period of time (more than 3 months).

\section{Procedure}

The study was part of a larger research project approved by the ethics committee of Jagiellonian University Medical College (KBET/122.6120.36.2015). The study began with a database search of health care centers as well as efforts to contact mothers whose children met the study's inclusion criteria. After receiving preliminary information about the study $63 \%$ of all contacted mothers agreed to participate. At the beginning of the first meeting we informed the participants of the procedure and the aim of the study, after which the mothers gave their written consent to participate, and the children gave their verbal consent. During the first meeting the mothers filled in questionnaires and participated in a short interview on the psychosocial functioning of their 
children. The children performed a short mentalizing task (Biased Mentalizing Task, BMT), which has been described elsewhere (Dejko 2017; Sharp and Fonagy 2008). As it was the preliminary phase of work on the Polish version of BMT, we decided that the data obtained was not reliable enough to be included in this study. A second meeting was organized, in which the mothers attended without their children and participated in AAI.

\section{Measures}

\section{Mothers' General Reflective Functioning}

To assess their reflective functioning the mothers participated in an Adult Attachment Interview. The AAI is a semistructured interview that focuses on childhood experiences of attachment (George et al. 1996). It is a well-established and widely validated research tool used in research on both attachment and mentalization (Van IJzendoorn 1995).

We applied the Reflective Functioning Scale (RFS; Fonagy et al. 1998) to the AAI to evaluate mother's RF. The RF coding is based on four main criteria: A. Awareness of the nature of mental states, B. Explicit effort to tease out mental states underlying behavior, C. Recognizing developmental aspects of mental states, and D. Mental states in relation to the interviewer. After rating each identified AAI passage separately and taking into account changes in narration dynamics, as well as the coherence of the narration as a whole, an overall rating is assigned to the interview. The overall rating ranges from -1 (negative RF) to 9 (exceptional RF; Allen et al. 2008).

According to validation studies of RFS, the scale possesses good psychometric properties (Fonagy et al. 1998; Taubner et al. 2012). In our study, two raters coded independently the AAI transcripts (the first two authors of the paper). The raters had been trained in the RF rating procedure at the Anna Freud Center and had successfully passed the validation procedure. The first rater coded all the transcripts, while the second rater coded randomly selected one-third of the transcripts. The inter-rater reliability was excellent (Krippendorff's alpha $=0.93 ; p<0.05$ ).

\section{Children's Externalizing Behavior Problems}

We applied the Child Behavior Checklist (CBCL) and Teacher Report Form (TRF) in the Polish version adapted by Wolańczyk (2002) to assess the severity of a child's externalizing behavior problems. The CBCL is a widely recognized caregiver report and the TRF is teacher report designed to identify problems in the psychosocial functioning of children aged 6-18 years. Both measures consist of 113 questions aimed at identifying internalizing and externalizing problems. Empirically based eight-syndrome subscales make it possible to create a profile that accurately illustrates the psychosocial functioning of child. In this study we decided to apply only Aggressive Behavior Scale and Rule-breaking Scale from CBCL and TRF, as these scales correspond to the aims of the study. The Polish version of the CBCL and TRF have been demonstrated to have good psychometric properties (Wolańczyk 2002). Wolańczyk (2002) reported alphas of .72 to .95 for the Aggressive Behavior Scale and Rule-breaking Scale for both the CBCL and TRF.

\section{A mother's Perception of Her Childhood Relationship with Her Caregivers}

To gauge the wider, intergenerational context of relationship quality we made use of the Polish version of the Parental Bonding Instrument (PBI; Parker et al. 1979; Popiel and Pragłowska 2006). The PBI retrospectively measures participants' perceptions of their relationship with their parents during their childhood and adolescence. The questionnaire consists of 25 items relating to a child's relationship with his or her mother and 25 parallel items concerning the child's relationship with his or her father. The items are rated using a 4-point, Likert-type scale. The perception of this relationship is assessed separately for the mother and the father in three dimensions: Care (e.g. Spoke to me with a warm and friendly voice), Overprotection (e.g. Tried to control everything I did) and Autonomy (e.g. Liked me to make my own decisions). A higher score on the Care Scale and the Autonomy Scale, indicates a higher quality relationship. A higher score on the Overprotection Scale indicates a poorer quality relationship. We used a three-factor PBI structure, as research conducted by Xu et al. (2016) has demonstrated that it fits the data better than two- or four-factor structure and it possesses satisfactory psychometric properties. Horecka-Lewitowicz (2006) reported alphas of 0.73 to 0.96 for mother-related and fatherrelated scales of Polish version of PBI.

\section{Socio-Demographics}

Information on demographics was provided from a structured questionnaire that included questions about place of residence, the age of the mother and child, the mother's education level, family structure as well as important events from the life of the child and his family. Other questions concerned the child's general health and development as well as the mental health care experiences of the mother and child.

\section{Data Analyses}

All the analyses were performed using the $\mathrm{R}$ Core Team (2018). Firstly, we conducted preliminary analyses (descriptive statistics and inter-correlations between 
variables). Secondly, we carried out regression analyses. We constructed separate models for each of the following scales serving as a dependent variable: the CBCL Aggressive Behavior Subscale, the CBCL Rule-breaking Subscale, the TRF Aggressive Behavior Subscale and the TRF RuleBreaking Subscale. The independent variables were the mother's RF and PBI Care, as well as the Overprotection and Autonomy Scales both for the mother and father. All the regression models contained the additive effects of RF and one of the selected PBI scales (e.g. Mother Care). We did not apply the Bonferroni correction because the results of the separate analyses were far from independent (the dependent variables were correlated, and the independent variables were correlated).

\section{Results}

\section{Preliminary Analyses}

First, the results of the preliminary analyses indicate that the mothers' education level was strongly associated with their RF level, $F(2,32)=5.90, p=0.006$. A post hoc Tukey test showed that mothers with primary or vocational education had a significantly lower level of RF $(M=1.6)$ than mothers with a secondary $(M=3.36)$ or higher education $(M=3.91)$ significantly at $p<0.05$. Other socio-demographic variables (mothers' age, place of residence) did not correlate significantly with any of the measured variables.

All the means and standard deviations of the measured variables are presented in Table 1 . To examine the links between a child's psychopathology and maternal factors (reflective functioning and the perception of a mother's childhood relationship with her parents), correlational analyses were used. The results are presented in Table 2.

\section{The Level of Mothers' General RF}

The mean level of RF in mothers was 3.03 ( $\mathrm{SD}=1.82$ ), which indicates an overall low level of mentalization skills in studied sample. We rated seventeen percent of the participants as having a negative or no RF. They tended to exhibit active and hostile resistance to mentalizing, as well as bizarre attributions, extreme concreteness and an absence of reflection. Fifty-two percent were rated as having a low RF level, which means that more than half of the participants tended to refer to mental states at a rudimentary level. Their references to mental states were rather general, unintegrated and detached from the individual's experience. Seventeen percent of the participants were rated as having an ordinary level of RF. Their narration regarding close relationships included a number of instances of reflection, even if they were lacking in complexity. Finally, fourteen percent of the sample was rated as having marked levels of $\mathrm{RF}$, which means that reflectiveness was maintained at a consistently high level.

\section{Associations between Maternal Factors and a Child's Psychopathology}

The associations between maternal factors (adult reflective functioning and a mother's perception of her childhood relationship with her parents) and child externalizing behavior difficulties, as reported by mother and teacher, are shown in Tables 3 and 4.

We found significant associations between maternal factors and a child's externalizing behavior as reported by his mother. RF had a significant negative effect on a child's aggressive behavior, when a child's aggressive behavior was regressed on RF and a mother's perception of her autonomy in her childhood relationship with her mother $(z=-3.00, p=0.005)$. A mother's RF was also a significant predictor of a child's aggressive behavior when other maternal variables were controlled for: PBI mother overprotection $(z=-2.65, p=0.013)$, PBI mother care $(z=-2.38, p=0.024)$, PBI father autonomy $(z=-2.77$, $p=0.009)$, and PBI father overprotection $(z=-2.28, p=$ $0.029)$. Other significant predictors of child aggressive behavior, where RF was controlled for, were a mother's perception of care in her childhood relationship with her father $(z=2.62, p=0.014)$ and autonomy in her childhood relationship with her mother $(z=-2.29, p=0.029)$. For more results, see Table 3 .

When a child's rule-breaking behavior was regressed on $\mathrm{RF}$ and a mother's perception of her autonomy in her childhood relationship with her mother RF had a significant negative effect $(z=-2.84, p=0.008)$. A mother's RF was also a significant predictor of child rule-breaking behavior when other maternal variables were controlled for: PBI mother overprotection $(z=-2.60, p=0.014)$, PBI mother care $(z=-2.40, p=0.022)$, PBI father autonomy $(z=$ $-2.98, p=0.005)$, and PBI father overprotection $(z=$ $-2.22, p=0.034)$. Other significant predictors of child rule-breaking behavior, where RF was controlled for, included a mother's perception of her autonomy in her childhood relationship with her father $(z=-2.19, p=$ $0.036)$ as well as with her mother $(z=-2.13, p=0.041)$. For more results, see Table 3.

No significant correlation was observed between a mother's RF or her perception of her childhood relationship with her parents and a teacher's reports of a child's aggressive and rule-breaking behavior. The results are reported in Table 4. 
Table 1 Descriptive statistics of a mother's reflective functioning, her child's psychopathology and her perception of her childhood relationship with her own parents

\begin{tabular}{lllrrrr}
\hline & Minimum & Maximum & M & SD & Skewness & Kurtosis \\
\hline Mother's RF & -1 & 7 & 3.03 & 1.82 & 0.14 & 0.11 \\
CBCL & & & & & & \\
Rule-breaking behavior & 1 & 12 & 5.77 & 3.36 & 0.38 & -1.07 \\
Aggressive behavior & 11 & 36 & 21.26 & 7.09 & 0.58 & -0.83 \\
TRF & & & & & & \\
Rule-breaking behavior & 0 & 18 & 6.84 & 4.54 & 0.65 & -0.24 \\
Aggressive behavior & 0 & 50 & 20.67 & 12.81 & 0.41 & -0.41 \\
PBI & & & & & & -0.23 \\
Mother care & 0 & 36 & 21.05 & 8.76 & -0.55 & -0.97 \\
Mother overprotection & 0 & 17 & 7.41 & 4.94 & 0.30 & -0.67 \\
Mother autonomy & 2 & 21 & 11.44 & 5.02 & -0.03 & -1.32 \\
Father care & 0 & 34 & 16.72 & 10.91 & -0.15 & 0.18 \\
Farther overprotection & 0 & 13 & 4.36 & 3.57 & 0.73 & -0.77 \\
Father autonomy & 2 & 21 & 13.41 & 5.20 & -0.15 & \\
\hline
\end{tabular}

$R F$ reflective function, $C B C L$ Child Behavior Checklist, TRF Teacher Report Form, PBI Parental Bonding Instrument

Table 2 Intercorrelations matrix between maternal factors (reflective functioning and perception of a mother's childhood relationship with her parents) and a child's internalizing and externalizing behavior problems as reported by mother and teacher on the CBCL

\begin{tabular}{|c|c|c|c|c|c|c|c|c|c|c|}
\hline & 1 & 2 & 3 & 4 & 5 & 6 & 7 & 8 & 9 & 10 \\
\hline $1 \mathrm{RF}$ & - & & & & & & & & & \\
\hline 2 PBI M Care & -0.06 & - & & & & & & & & \\
\hline 3 PBI M Op. & 0.27 & -0.16 & - & & & & & & & \\
\hline 4 PBI M Aut. & $-0.35^{*}$ & 0.21 & $-0.57 * *$ & - & & & & & & \\
\hline 5 PBI F Care & -0.17 & $0.35 *$ & -0.09 & -0.16 & - & & & & & \\
\hline 6 PBI F Op. & 0.06 & -0.07 & $0.51 * *$ & $-0.39 *$ & 0.18 & - & & & & \\
\hline 7 PBI F Aut. & -0.42 & -0.02 & $-0.33^{*}$ & $0.61 * *$ & -0.06 & $-0.43 *$ & - & & & \\
\hline 8 CBCL Aggr. & $-0.41 *$ & -0.04 & 0.21 & -0.30 & $0.40 *$ & $0.38 *$ & -0.24 & - & & \\
\hline 9 CBCL R-br. & -0.32 & -0.10 & 0.20 & -0.28 & 0.10 & $0.41 *$ & -0.24 & $0.73 * *$ & - & \\
\hline 10 TRF Aggr. & -0.05 & -0.20 & 0.03 & 0.04 & -0.24 & -0.26 & 0.16 & -0.01 & -0.02 & - \\
\hline 11 TRF R-br. & -0.28 & -0.26 & -0.11 & 0.25 & -0.25 & -0.24 & 0.26 & 0.07 & 0.14 & $0.84 * *$ \\
\hline
\end{tabular}

$R F$ reflective function, $P B I$ Parental Bonding Instrument, $M$ mother, $F$ father, Op. overprotection, Aut autonomy, Aggr. aggressive behavior, $R$ - $b r$. rule-breaking behavior, $C B C L$ Child Behavior Checklist, TRF Teacher Report Form

$* p<0.05 ; * * p<0.001$

\section{Discussion}

The aim of our study was to examine the associations between a child's externalizing problems, a mother's general RF and her perception of her childhood relationship with her own caregivers. We decided to study a clinical sample of school-aged boys, as research shows that this group might experience more problems with emotion and behavior regulation (Denham et al. 2000; Hill et al. 2006; Weis et al. 2013). In support of our predictions, we observed that higher levels of aggressive and rule-breaking behavior in children reported by mothers were associated with lower levels of mother's mentalization and her perception of poorer childhood relationship with her own caregivers. Our analysis did not reveal any significant association between maternal factors and child externalizing behavior reported by teachers. One possible explanation for this finding is that mothers, due to their emotional engagement, are less objective observers of child behavior compared to teachers. Mothers with lower RF in particular might project their feelings onto the child (Ensink et al. 2017) or engage in a process known as prementalizing, which hinders their perception of child behavior and underlying mental states (Rutherford et al. 2016). However, recent research conducted by Borelli et al. (2017) pointed out that a low RF may facilitate observation of such behavior, as it is associated with a greater focus on events occurring in the external world, and therefore it may result 
Table 3 Regression analyses for predicting CBCL child aggressive and rule-breaking behavior reported by mother
Table 4 Regression analyses for predicting child aggressive and rule-breaking behavior reported by teacher

\begin{tabular}{|c|c|c|c|c|c|c|c|c|}
\hline & \multicolumn{4}{|c|}{ CBCL aggressive behavior } & \multicolumn{4}{|c|}{ CBCL rule-breaking behavior } \\
\hline & Estimate & SE & $z$ & $p$ & Estimate & SE & $z$ & $p$ \\
\hline \multicolumn{9}{|c|}{ RF: PBI mother autonomy } \\
\hline $\mathrm{RF}$ & -1.89 & 0.63 & -3.00 & 0.005 & -0.89 & 0.31 & -2.84 & 0.008 \\
\hline Autonomy & -0.52 & 0.23 & -2.29 & 0.029 & -0.24 & 0.11 & -2.13 & 0.041 \\
\hline \multicolumn{9}{|c|}{ RF: PBI mother overprotection } \\
\hline $\mathrm{RF}$ & -1.71 & 0.64 & -2.65 & 0.013 & -0.82 & 0.31 & -2.60 & 0.014 \\
\hline Control & 0.38 & 0.24 & 1.62 & 0.116 & 0.20 & 0.12 & 1.72 & 0.095 \\
\hline \multicolumn{9}{|c|}{ RF: PBI mother care } \\
\hline $\mathrm{RF}$ & -1.58 & 0.66 & -2.38 & 0.024 & -0.77 & 0.32 & -2.40 & 0.022 \\
\hline Care & -0.10 & 0.14 & -0.70 & 0.490 & -0.08 & 0.07 & -1.12 & 0.270 \\
\hline \multicolumn{9}{|c|}{ RF: PBI father autonomy } \\
\hline RF & -1.88 & 0.68 & -2.77 & 0.009 & -0.96 & 0.32 & -2.98 & 0.005 \\
\hline Autonomy & -0.37 & 0.23 & -1.59 & 0.122 & -0.24 & 0.11 & -2.19 & 0.036 \\
\hline \multicolumn{9}{|c|}{ RF: PBI father overprotection } \\
\hline $\mathrm{RF}$ & -1.43 & 0.63 & -2.28 & 0.029 & -0.67 & 0.30 & -2.22 & 0.034 \\
\hline Control & 0.50 & 0.30 & 1.66 & 0.108 & 0.29 & 0.15 & 1.99 & 0.055 \\
\hline \multicolumn{9}{|c|}{ RF: PBI father care } \\
\hline $\mathrm{RF}$ & -0.96 & 0.62 & -1.53 & 0.136 & -0.67 & 0.34 & -1.99 & 0.056 \\
\hline Care & 0.27 & 0.10 & 2.62 & 0.014 & 0.01 & 0.06 & 0.24 & 0.814 \\
\hline
\end{tabular}

The table presents results from separate regression analyses for each PBI scale

$C B C L$ Child Behavior Checklist, $R F$ reflective functioning, $P B I$ Parental Bonding Instrument

\begin{tabular}{|c|c|c|c|c|c|c|c|c|}
\hline & \multicolumn{4}{|c|}{ TRF aggressive behavior } & \multicolumn{4}{|c|}{ TRF rule-breaking behavior } \\
\hline & Estimate & SE & $z$ & $p$ & Estimate & SE & $z$ & $p$ \\
\hline \multicolumn{9}{|c|}{ RF: PBI mother autonomy } \\
\hline $\mathrm{RF}$ & -0.27 & 1.45 & -0.19 & 0.851 & -0.52 & 0.48 & -1.08 & 0.288 \\
\hline Autonomy & 0.11 & 0.49 & 0.23 & 0.823 & 0.18 & 0.16 & 1.07 & 0.293 \\
\hline \multicolumn{9}{|c|}{ RF: PBI mother overprotection } \\
\hline $\mathrm{RF}$ & -0.46 & 1.39 & -0.33 & 0.744 & -0.67 & 0.47 & -1.42 & 0.166 \\
\hline Control & 0.08 & 0.52 & 0.16 & 0.871 & -0.06 & 0.18 & -0.34 & 0.734 \\
\hline \multicolumn{9}{|c|}{ RF: PBI mother care } \\
\hline $\mathrm{RF}$ & -0.41 & 1.32 & -0.31 & 0.761 & -0.72 & 0.44 & -1.63 & 0.114 \\
\hline Care & -0.27 & 0.27 & -1.00 & 0.327 & -0.12 & 0.09 & -1.39 & 0.176 \\
\hline \multicolumn{9}{|c|}{ RF: PBI father autonomy } \\
\hline RF & 0.06 & 1.42 & 0.04 & 0.968 & -0.53 & 0.48 & -1.10 & 0.282 \\
\hline Autonomy & 0.41 & 0.47 & 0.87 & 0.393 & 0.17 & 0.16 & 1.06 & 0.296 \\
\hline \multicolumn{9}{|c|}{ RF: PBI father overprotection } \\
\hline $\mathrm{RF}$ & -0.24 & 1.30 & -0.18 & 0.856 & -0.67 & 0.45 & -1.50 & 0.144 \\
\hline Control & -0.88 & 0.62 & -1.43 & 0.163 & -0.25 & 0.21 & -1.17 & 0.253 \\
\hline \multicolumn{9}{|c|}{ RF: PBI father care } \\
\hline $\mathrm{RF}$ & -0.66 & 1.31 & -0.50 & 0.618 & -0.82 & 0.44 & -1.87 & 0.072 \\
\hline Care & -0.31 & 0.22 & -1.42 & 0.165 & -0.12 & 0.07 & -1.70 & 0.099 \\
\hline
\end{tabular}

The table presents results from separate regression analyses for each PBI scale

$T R F$ Teacher Report Form; $R F$ reflective functioning, PBI Parental Bonding Instrument 
in more adequate reporting of externalizing behavior symptoms. It is also possible that school and home environments evoke different displays of problematic behavior in children.

Our analysis revealed a low level of RF in mothers, which is lower than RF in securely attached mothers as reported by Fonagy et al. (1991), and RF in mothers whose school-age children suffer from anxiety problems (Esbjørn et al. 2013). Mothers' capacity to reflect on their own emotions is significantly compromised in the studied sample and resembles typical RF scores of insecurely attached mothers (Fonagy et al. 1991) or self-reflection scores noted in mothers with substance use disorders (Suchman et al. 2010). It is interesting that RF levels in the mothers who participated in our study turned out to be lower than we would expect for a middle or high SES sample. Our results might be better understood in light of data on SES gathered with more objective measures (instead of mothers' declarations), as well as data concerning mothers' general psychological functioning.

The results of our study are consistent with other research which has shown a correlation between compromised mentalizing in a mother and the externalizing behavior of a child (Centifanti et al. 2016; Ensink et al. 2017; Meins et al. 2013; Sharp et al. 2007). The underlying mechanisms are possibly transactional. A low RF in a mother hinders her self-understanding and affects both regulation and impulse control (Fonagy and Target 1997; Fonagy et al. 2002), leading to less sensitive and thoughtful responses to the child (Ensink et al. 2016; Finzi-Dottan et al. 2006; Suchman et al. 2010), and as a result possibly continuing a child's behavioral problems. The behavior of a more difficult child in turn is harder to understand and might require better mentalization in the parent. When interactions with the child are intense and evoke anger, helplessness, criticism or withdrawal, a mother's compromised mentalizing can contribute to a vicious cycle of heightening tension, resulting in maintaining or even aggravating the child's oppositional, disobedient or rulebreaking behavior (Stormshak et al. 2000).

Various studies have shown a correlation between low RF levels in parents and poor-quality caregiving (Borelli et al. 2012; Grienenberger et al. 2005; Huth-Bocks et al. 2014; Rosenblum et al. 2008; Stacks et al. 2014) and negative parenting behaviors (Ensink et al. 2016), which in turn contributes to oppositional and aggressive child behavior (Patterson 1986; Stormshak et al. 2000). Although parenting practices have not been included in our study, they may play an important role, as Stormshak et al. (2000) showed that coercive and punitive parenting tends to aggravate a child's oppositional, aggressive or hyperactive behavior. Associations between a mothers' capacity to mentalize her own mental states, parenting practices and a child's externalizing behavior problems require further research.

Our study showed that the mothers of boys exhibiting more severe aggressive and disobedient behavior described their childhood relationship with their parents as one in which their autonomy was restricted. A limited experience of autonomy in a mother's childhood relationship with her parents might make it more difficult for her to understand and support her school-aged child's growing independence. In such a context, a child's aggressive and disobedient behavior might be seen as a struggle for more understanding and support for his need for growing autonomy and self-reliance (Namysłowska 2004). It is also possible that a less autonomous mother's relationship with her attachment figures has influenced her perception of her child's disobedient behavior in such a way that she sees it as being more severe than it may actually be. Furthermore, we achieved a surprising result, which is positive association observed between a mother's perception of care in her childhood relationship with her father and her son's aggressive behavior. There might be two potential explanations for this. First, we assume that in cases where a mother's childhood relationship with her father was more positive, there were fewer opportunities for them to experience and learn how to deal with difficult interchanges, conflicts or ruptures in interaction. It might also be more difficult to express anger and opposition against a highly caring father. As a consequence, the ability of a mother to identify, regulate and express feelings in her relationship with her son might be hindered (Jurist 2005). Secondly, a mother's expectations of a close, warm and caring relationship (possibly related to her idealization of father) might be transferred to her relationship with her son, without acknowledging the specific needs and challenges that characterize this relationship.

In our study we applied widely recognized research tools and the conclusions are interesting and potentially important. However, our study has some limitations, as a consequence of which the findings are rather exploratory and must be replicated in further research before firm conclusions can be drawn for clinical practice. The sample size is modest. Hence, any conclusions should be made with caution. An analysis does not allow for any inferences to be made regarding causal associations. We assume that these associations are complex and transactional, and possibly mediated by such factors as emotion regulation, parenting practices and child's mentalization. However, we could not examine these mediating factors with our study design. The absence of a control group precludes drawing any conclusions about specific and discriminative characteristics of the sample, and the inclusion of boys precludes any inferences concerning girls. The majority of mothers who participated in the study were Caucasian from 
middle or high a SES background, which makes it impossible to draw any conclusions about mothers from a more adverse socioeconomic environment, as well as from different ethnical background. The absence of boys' fathers from the study makes the picture somehow narrow and incomplete, as research shows that the involvement of the father is a significant determinant of a child's development (Barker et al. 2017; Benbassat and Priel 2015; Denham et al. 2000; Duhig et al. 2002; Esbjørn et al. 2013). There is also a need for further research on the subject which would include more objective measures of a child's psychosocial functioning (Fearon and Belsky 2011), as well as information regarding parenting practices, as well as parental attitudes and approaches to raising children (Denham et al. 2000; Stormshak et al. 2000). Our article presents the preliminary results and further research is needed before practical conclusions can be drawn.

Due to the paucity of research aimed at understanding the psychosocial functioning of school-age children from a mentalization perspective (Borelli et al. 2016; Esbjørn et al. 2013; Sharp et al. 2007), and bearing in mind the preliminary nature of the results presented in this article, further research in this area should be continued. In spite of the limitations of our study, our findings show interesting associations between a mother's general RF and the perceived quality of her childhood relationship with her parents, and the severity of externalizing behavior in already diagnosed children. Hence, we believe research on psychotherapeutic interventions that focus on a mother's RF are crucial. Although RF in parents is currently regarded as a vital intervention target, existing research and clinical programs promote RF mainly among parents of infants and toddlers (Borelli et al. 2016; Grienenberger et al. 2005). Mentalization-based therapeutic programs for parents of school-age children require more research and clinical attention.

Funding This study was funded by Jagiellonian University Medical College (grant number K/DSC/003069).

Author Contributions KDW: formulated the problem and hypotheses, designed and executed the study, analyzed the data, interpreted the results, and wrote the paper. B. Janusz: collaborated in formulation of the problem and hypotheses, designing of the study, interpretation of the results, writing and editing of the final manuscript. B. Józefik: collaborated in formulation of the problem and hypotheses, designing of the study and editing of the final manuscript.

\section{Compliance with Ethical Standards}

Conflict of Interest KDW received research grant from Jagiellonian University Medical College. The author declares that she does not have any other conflict of interest. The other authors declare that they have no conflict of interest.

Ethical Approval All procedures performed in studies involving human participants were in accordance with the ethical standards of the institutional research committee in Jagiellonian University Medical College (KBET/122.6120.36.2015) and with the 1964 Helsinki declaration and its later amendments or comparable ethical standards. This article does not contain any studies with animals performed by any of the authors.

Informed Consent Informed consent was obtained from all individual participants included in the study.

Publisher's note Springer Nature remains neutral with regard to jurisdictional claims in published maps and institutional affiliations.

Open Access This article is distributed under the terms of the Creative Commons Attribution 4.0 International License (http://crea tivecommons.org/licenses/by/4.0/), which permits unrestricted use, distribution, and reproduction in any medium, provided you give appropriate credit to the original author(s) and the source, provide a link to the Creative Commons license, and indicate if changes were made.

\section{References}

Allen, J. G., Fonagy, P., \& Bateman, A. W. (2008). Mentalizing in clinical practice. Washington, DC: American Psychiatric Publishing, Inc.

Arnott, B., \& Meins, E. (2007). Links between antenatal attachment representations, postnatal mind-mindedness, and infant attachment security: a preliminary study of mothers and fathers. Bulletin of Menninger Clinic, 71, 132-149. https://doi.org/10.1521/ bumc.2007.71.2.132.

Bailey, J. A., Hill, K. G., Oesterle, S., \& Hawkins, J. D. (2009). Parenting practices and problem behavior across three generations: monitoring, harsh discipline, and drug use in the intergenerational transmission of externalizing behavior. Developmental Psychology, 45(5), 1214-1226. https://doi.org/10. 1037/a0016129.

Barker, B., Iles, J. E., \& Ramchandani, P. G. (2017). Fathers, fathering and child psychopathology. Current Opinion in Psychology, 15, 87-92. https://doi.org/10.1016/j.copsyc.2017.02.015.

Benbassat, N., \& Priel, B. (2012). Parenting and adolescent adjustment: the role of parental reflective function. Journal of Adolescence, 35 , 163-174. https://doi.org/10.1016/j.adolescence.2011.03.004.

Benbassat, N., \& Priel, B. (2015). Why is fathers' reflective function important? Psychoanalytic Psychology, 32, 1-22. https://doi.org/ 10.1037/a0038022.

Beyers, J. M., Bates, J. E., Pettit, G. S., \& Dodge, K. A. (2003). Neighborhood structure, parenting processes, and the development of youth's externalizing behaviors: a multilevel analysis. American Journal of Community Psychology, 31(1-2), 35-53. https://doi.org/10.1023/A:1023018502759.

Bizzi, F., Ensink, K., Borelli, J. L., Charpentier Mora, S., \& Cavanna, D. (2019). Attachment and reflective functioning in children with somatic symptom disorders and disruptive behavior disorders. European Child \& Adolescent Psychiatry, 28(5), 705-711. https://doi.org/10.1007/s00787-018-1238-5.

Borelli, J. L., Palmer, A., Vanwoerden, S., \& Sharp, C. (2017). Convergence in reports of adolescents' psychopathology: a focus on disorganized attachment and reflective functioning. Journal of Clinical Child \& Adolescent Psychology, 48(4), 1-14. https://doi. org/10.1080/15374416.2017.1399400.

Borelli, J. L., St.John, H. K., Cho, E., \& Suchman, N. E. (2016). Reflective functioning in parents of school-aged children. American Journal of Orthopsychiatry, 86(1), 25-36. https://doi. org/10.1037/ort0000141. 
Borelli, J. L., West, J. L., Decoste, C., \& Suchman, N. E. (2012). Emotionally avoidant language in the parenting interviews of substance-dependent mothers: associations with reflective functioning, recent substance use, and parenting behavior. Infant Mental Health Journal, 33, 506-519. https://doi.org/10.1002/ imhj.21340.

Bosmans, G., \& Kerns, K. A. (2015). Attachment in middle childhood: progress and prospects. New Directions for Child and Adolescent Development, 148, 1-14. https://doi.org/10.1002/cad.20100.

Bowen, M. (1978). Family therapy in clinical practice. Northvale, NJ: Jason Aronson Inc.

Bowlby, J. (1973). Attachment and loss: Vol 2. Separation, anxiety and anger. London: Pengiun Books.

Camoirano, A. (2017). Mentalizing makes parenting work: a review about parental reflective functioning and clinical interventions to improve it. Frontiers in Psychology, 8(Jan), 1-12. https://doi.org/ 10.3389/fpsyg.2017.00014.

Centifanti, L. C. M., Meins, E., \& Fernyhough, C. (2016). Callous unemotional traits and impulsivity: Distinct longitudinal relations with mind-mindedness and understanding of others. Journal of Child Psychology and Psychiatry, 57(1), 84-92. https://doi.org/ $10.1111 /$ jcpp. 12445 .

Cepeda, C. (2012). Badanie psychiatryczne dzieci i młodzieży. Podręcznik kliniczny. Wrocław: Elsevier Urban \& Partner.

Dejko, K 2017). Analiza zwiazków pomiędzy uwarunkowaniami zdolności regulacji emocjonalnej matki a funkcjonowaniem psychospotecznym dziecka. Cracow: Jagiellonian University. Unpublished manuscript.

Denham, S. A., Workman, E., Cole, P. M., Weissbrod, C., Kendziora, K. T., \& Zahn-Waxler, C. (2000). Prediction of externalizing behavior problems from early to middle childhood: The role of parental socialization and emotion expression. Development and Psychopathology, 12(1), 23-45. https://doi.org/10.1017/ S0954579400001024.

Duhig, A. M., Phares, V., \& Birkeland, R. W. (2002). Involvement of fathers in therapy: a survey of clinicians. Professional Psychology Research and Practice, 33(4), 389-395. https://doi.org/10.1037/ 0735-7028.33.4.389.

Egeland, B., \& Kreutzer, T. (1991). A longitudinal study of the effects of maternal stress and protective factors on the development of high risk children. In E. M. Cummings, A. L. Greene \& K. H. Karraker (Eds.), Lifespan developmental psychology: perspectives on stress and coping (pp. 61-85). Hillsdale, NJ: Erlbaum.

Ensink, K., Bégin, M., Normandin, L., \& Fonagy, P. (2016). Maternal and child reflective functioning in the context of child sexual abuse: pathways to depression and externalising difficulties. European Journal of Psychotraumatology, 7(1), 30611. https:// doi.org/10.3402/ejpt.v7.30611.

Ensink, K., Leroux, A., Normandin, L., Biberdzic, M., \& Fonagy, P. (2017). Assessing reflective parenting in interaction with schoolaged children. Journal of Personality Assessment, 99(6), 585-595. https://doi.org/10.1080/00223891.2016.1270289.

Ensink, K., Normandin, L., Plamondon, A., Berthelot, N., \& Fonagy, P. (2016). Intergenerational pathways from reflective functioning to infant attachment through parenting. Canadian Journal of Behavioural Science, 48(1), 9-18. https://doi.org/10.1037/ cbs0000030.

Esbjørn, B. H., Pedersen, S. H., Daniel, S. I. F., Hald, H. H., Holm, J. M., \& Steele, H. (2013). Anxiety levels in clinically referred children and their parents: examining the unique influence of selfreported attachment styles and interview-based reflective functioning in mothers and fathers. British Journal of Clinical Psychology, 52(4), 394-407. https://doi.org/10.1111/bjc.12024.

Fearon, R. M., \& Belsky, J. (2011). Infant-mother attachment and the growth of externalizing problems across the primary-school years. Journal of Child Psychology and Psychiatry and Allied
Disciplines, 52(7), 782-791. https://doi.org/10.1111/j.1469-7610. 2010.02350.x.

Finzi-Dottan, R., Manor, I., \& Tyano, S. (2006). ADHD, temperament, and parental style as predictors of the child's attachment patterns. Child Psychiatry and Human Development, 37(2), 103-114. https://doi.org/10.1007/s10578-006-0024-7.

Fonagy, P. (2004a). Early-life trauma and the psychogenesis and prevention of violence. Annals of the New York Academy of Sciences, 1036, 181-200. https://doi.org/10.1196/annals.1330.012.

Fonagy, P. (2004b). The developmental roots of violence in the failure of mentalization. In F. Pfafflin \& G. Adshead (Eds.), A matter of security. The application of attachment theory to forensic psychiatry and psychotherapy (pp. 13-56). London: Jessica Kingsley Publishers.

Fonagy, P., Gergely, G., Jurist, E. L., \& Target, M. (2002). Affect regulation, mentalization, and the development of the self. London: Karnac.

Fonagy, P., Luyten, P., Moulton-Perkins, A., Lee, Y.-W., Warren, F., \& Howard, S., et al. (2016). Development and validation of a self-report measure of mentalizing: The reflective functioning questionnaire. PLOS ONE, 11(7), e0158678. https://doi.org/10. 1371/journal.pone.0158678.

Fonagy, P., Luyten, P., \& Strathearn, L. (2011). Borderline personality disorder, mentalization and the neurobiology of attachment. Infant Mental Health Journal, 32(1), 47-69. https://doi.org/10. 1002/imhj.20283.

Fonagy, P., Steele, M., Steele, H., Moran, G. S., \& Higgitt, A. C. (1991). The capacity for understanding mental states: the reflective self in parent and child and its significance for security of attachment. Infant Mental Health Journal, 12(3), 201-218. https://doi.org/10.1002/1097-0355(199123)12:33.0.CO;2-7.

Fonagy, P., \& Target, M. (1997). Attachment and reflective function: their role in self-organization. Development and Psychopathology, 9(4), 679-700. https://doi.org/10.1017/S0954579497001399.

Fonagy, P., Target, M., Steele, H., \& Steele, M. (1998). Reflectivefunctioning manual. Version 5. London. Unpublished manuscript.

George, C, Kaplan, N., \& Main, M. 1996). Adult attachment interviewrd edition Berkeley: Department of Psychology, University of California. Unpublished manuscript.

Gershoff, E. T. (2002). Corporal punishment by parents and associated child behaviors and experiences: a meta-analytic and theoretical review. Psychological Bulletin, 128(4), 539-579. https://doi.org/ 10.1037/0033-2909.128.4.539.

Grienenberger, J. F., Kelly, K., \& Slade, A. (2005). Maternal reflective functioning, mother-infant affective communication, and infant attachment: exploring the link between mental states and observed caregiving behavior in the intergenerational transmission of attachment. Attachment \& Human Development, 7(3), 299-311. https://doi.org/10.1080/14616730500245963.

Hausberg, M. C., Schulz, H., Piegler, T., Happach, C. G., Klöpper, M., Brütt, A. L., Sammet, I., \& Andreas, S. (2012). Is a self-rated instrument appropriate to assess mentalization in patients with mental disorders? Development and first validation of the Mentalization Questionnaire (MZQ). Psychotherapy Research, 22(6), 699-709. https://doi.org/10.1080/10503307.2012.709325.

Hill, A. L., Degnan, K. A., Calkins, S. D., \& Keane, S. P. (2006). Profiles of externalizing behavior problems for boys and girls across preschool: The roles of emotion regulation and inattention. Developmental Psychology, 42(5), 913-928. https://doi.org/10. 1037/0012-1649.42.5.913.

Hill, J. (2002). Biological, psychological and social processes in the conduct disorders. Journal of Child Psychology and Psychiatry, 43(1), 133-164. https://doi.org/10.1111/1469-7610.00007.

Hill, J., Fonagy, P., Lancaster, G., \& Broyden, N. (2007). Aggression and intentionality in narrative responses to conflict and distress story stems: an investigation of boys with disruptive behaviour 
problems. Attachment \& Human Development, 9(3), 223-237. https://doi.org/10.1080/14616730701453861.

Horecka - Lewitowicz, A 2006). Czynniki rodzinne i wybrane uwarunkowania socjalno-bytowe $w$ grupie dzieci 10-16 lat $z$ rozpoznaniem zaburzen zachowania. Warsaw: The Institute of Psychiatry and Neurology. Unpublished manuscript.

Huth-Bocks, A. C., Muzik, M., Beeghly, M., Earls, L., \& Stacks, A. M. (2014). Secure base scripts are associated with maternal parenting behavior across contexts and reflective functioning among trauma-exposed mothers. Attachment \& Human Development, 16, 535-556. https://doi.org/10.1080/14616734.2014.967787.

Jurist, E. L. (2005). Mentalized affectivity. Psychoanalytic Psychology, 22(3), 426-444. https://doi.org/10.1037/0736-9735.22.3.426.

Katz, L. F., \& Windecker-Nelson, B. (2004). Parental meta-emotion philosophy in families with conduct-problem children: links with peer relations. Journal of Abnormal Child Psychology, 32(4), 385-398. https://doi.org/10.1023/B:JACP.0000030292.36168.30.

Main, M. (1993). Metacognitive knowledge, metacognitive monitoring, and singular (coherent) vs. multiple (incoherent) model of attachment. Findings and directions for future research. In C. M. Parkes, J. Stevenson-Hinde \& P. Marris (Eds), Attachment Across the Life Cycle (pp. 127-156). Florence, KY: Routledge.

Mazursky-Horowitz, H., Felton, J. W., MacPherson, L., Ehrlich, K. B., Cassidy, J., Lejuez, C. W., \& Chronis-Tuscano, A. (2015). Maternal emotion regulation mediates the association between adult attention-deficit/hyperactivity disorder symptoms and parenting. Journal of Abnormal Child Psychology, 43(1), 121-131. https://doi.org/10.1007/s10802-014-9894-5.

McGoldrick, M., Gerson, R., \& Shellenberger, S. (1999). Genograms. Assessment and intervention. Second Edition London: W.W. Norton \& Company.

Meins, E., Centifanti, L. C. M., Fernyhough, C., \& Fishburn, S. (2013). Maternal mind-mindedness and children's behavioral difficulties: mitigating the impact of low socioeconomic status. Journal of Abnormal Child Psychology, 41(4), 543-553. https:// doi.org/10.1007/s10802-012-9699-3.

Namysłowska, I. (2004). Późne dzieciństwo- wiek szkolny. In I. Namysłowska (Ed.), Psychiatria dzieci $i$ młodzieży (pp. 171-177). Warsaw: Wydawnictwo Lekarskie PZWL.

Parker, G., Tupling, H., \& Brown, L. (1979). Parental bonding instrument. British Journal of Medical Psychology, 52, 1-10. https://doi.org/10.1111/j.2044-8341.1979.tb02487.x.

Patterson, G. R. (1986). Performance models for antisocial boys. American Psychologist, 41, 432-444.

Popiel, A., \& Pragłowska, E. (2006). Terapia poznawczobehawioralna schizofrenii. In J. Meder (Ed.), Oddziatywania psychologiczne $w$ schizofrenii. Biblioteka Psychiatrii Polskiej (pp. 31-43). Cracow: Komitet Redakcyjno-Wydawniczy PTP.

R Core Team. (2018). R: a language and environment for statistical computing. Vienna, Austria: R Foundation for Statistical Computing. https://www.R-project.org/.

Rosenblum, K. L., McDonough, S., Sameroff, A. J., \& Muzik, M. (2008). Reflection in thought and action: Maternal parenting reflectivity predicts mind-minded comments and interactive behavior. Infant Mental Health Journal, 29, 362-376. https://doi. org/10.10002/imhj.20184.

Rosso, A. M., Viterbori, P., \& Scopesi, A. M. (2015). Are maternal reflective functioning and attachment security associated with preadolescent mentalization? Frontiers in Psychology, 6(AUG), 1-12. https://doi.org/10.3389/fpsyg.2015.01134.

Rutherford, H. J., Maupin, A. N., Landi, N., Potenza, M. N., \& Mayes, L. C. (2016). Parental reflective functioning and the neural correlates of processing infant affective cues. Social Neuroscience, 12, 519-529. https://doi.org/10.1080/17470919. 2016.1193559.
Sharp, C., Croudace, T. J., \& Goodyer, I. M. (2007). Biased mentalizing in children aged seven to 11: Latent class confirmation of response styles to social scenarios and associations with psychopathology. Social Development, 16(1), 181-202. https://doi. org/10.1111/j.1467-9507.2007.00378.x.

Sharp, C., \& Fonagy, P. (2008). The parent's capacity to treat the child as a psychological agent: constructs, measures and implications for developmental psychopathology: topic review. Social Development, 17(3), 737-754. https://doi.org/10.1111/j.1467-9507. 2007.00457.x.

Slade, A. (2005). Parental reflective functioning: an introduction. Attachment \& Human Development, 7(3), 269-281. https://doi. org/10.1080/14616730500245906.

Slade, A., Grienenberger, J., Bernbach, E., Levy, D., \& Locker, A. (2005). Maternal reflective functioning, attachment, and the transmission gap: a preliminary study. Attachment \& Human Development, 7(3), 283-298. https://doi.org/10.1080/14616730500245880.

Smaling, H. J. A., Huijbregts, S. C. J., van der Heijden, K. B., Hay, D. F., van Goozen, S. H. M., \& Swaab, H. (2017). Prenatal reflective functioning and development of aggression in infancy: The roles of maternal intrusiveness and sensitivity. Journal of Abnormal Child Psychology, 45(2), 237-248. https://doi.org/10. 1007/s10802-016-0177-1.

Smaling, H. J. A., Huijbregts, S. C. J., van der Heijden, K. B., van Goozen, S. H. M., \& Swaab, H. (2016). Maternal reflective functioning as a multidimensional construct: differential associations with children's temperament and externalizing behavior. Infant Behavior and Development, 44, 263-274. https://doi.org/ 10.1016/j.infbeh.2016.06.007.

Stacks, A. M., Muzik, M., Wong, K., Beeghly, M., Huth-Bocks, A., \& Irwin, J. L., et al. (2014). Maternal reflective functioning among mothers with childhood maltreatment histories: Links to sensitive parenting and infant attachment security. Attachment \& Human Development, 16, 515-533. https://doi.org/10.1080/14616734. 2014.935452.

Stormshak, E. A., Bierman, K. L., McMahon, R. J., \& Lengua, L. J. (2000). Parenting practices and child disruptive behavior problems in early elementary school. Conduct problems prevention research group. Journal of Clinical Child Psychology, 29(1), 30-42. https://doi.org/10.1207/S15374424jccp2901_3.

Suchman, N. E., Decoste, C., Castiglioni, N., Mcmahon, T. J., Rounsaville, B., \& Mayes, L. (2010). The Mothers and Toddlers program, an attachment-based parenting intervention for substance-using women: results at 6-week follow-up in a randomized clinical pilot. Infant Mental Health Journal, 32(4), 427-449. https://doi.org/10.1002/imhj.20303.

Suchman, N. E., DeCoste, C., Leigh, D., \& Borelli, J. (2010). Reflective functioning in mothers with drug use disorders: Implications for dyadic interactions with infants and toddlers. Attachment \& Human Development, 12(6), 567-585. https://doi. org/10.1080/14616734.2010.501988.

Taubner, S., Hörz, S., Fischer-Kern, M., Doering, S., Buchheim, A., \& Zimmermann, J. (2012). Internal structure of the Reflective Functioning Scale. Psychological Assessment, 25(1), 127-135. https://doi.org/10.1037/a0029138.

Van IJzendoorn, M. (1995). Adult attachment representations, parental responsiveness, and infant attachment: A meta-analysis on the predictive validity of the adult attachment interview. Psychological Bulletin, 117(3), 387-403. https://doi.org/10.1037/00332909.117.3.387.

Weis, M., Heikamp, T., \& Trommsdorff, G. (2013). Gender differences in school achievement: the role of self-regulation. Frontiers in Psychology, 4(JUL), 1-10. https://doi.org/10.3389/fpsyg.2013.00442.

White, R., \& Renk, K. (2012). Externalizing behavior problems during adolescence: an ecological perspective. Journal of Child and 
Family Studies, 21, 158-171. https://doi.org/10.1007/s10826011-9459-y.

Wolańczyk, T. (2002). Zaburzenia emocjonalne $i$ behawioralne $u$ dzieci i młodzieży szkolnej w Polsce. Warsaw: Medical Academy. Unpublished manuscript.

Xu, M. K., Morin, A. J. S., Marsh, H. W., Richards, M., \& Jones, P. B. (2016). Psychometric validation of the Parental Bonding Instrument in a U.K. population-based sample: Role of gender and association with mental health in mid-late life. Assessment, 25(6), 716-728. https://doi.org/10.1177/1073191116660813.

Yates, T. M., Obradović, J., \& Egeland, B. (2010). Transactional relations across contextual strain, parenting quality, and early childhood regulation and adaptation in a high-risk sample. Development and Psychopathology, 22(3), 539-55. https://doi. org/10.1017/S095457941000026X. 